\title{
Mineralogy of some evolved LL chondrites with reference to asteroid materials and solar system evolution
}

\author{
Hiroshi Takeda ${ }^{1,2^{*}}$, Hiroshi Nagaoka ${ }^{3}$, Akira Yamaguchi ${ }^{4,5}$, Yuzuru Karouji ${ }^{6}$ and Yuuki Yazawa ${ }^{7}$
}

\begin{abstract}
Mineralogy of three LL chondrites including Y-981971, Y-793214, and Y-790782 indicates that granulitic materials may have been formed in some depth of their parent body by an impact event. This process of high-temperature episodes is different from the records in the differentiated achondrites (howardite-eucrite-diogenite (HED)) possibly from the Vesta-like asteroid.
\end{abstract}

Keywords: LL chondrite; Partial melting; Metamorphism; Differentiation; Pyroxene; Olivine

\section{Findings} Introduction

Because of the recent investigations on the returned dusts from the Itokawa by the Hayabusa Mission (e.g., Nakamura et al. 2011), we have a renewed interest in the LL chondrites in order to better understand the evolutional processes on an asteroidal body. Nakamura et al. (2011) reported that Itokawa dusts have LL composition. It is generally believed that the chondritic materials preserve the chemical records of the primitive solar system materials (Fujiwara et al. 2006). Shock partial melting and recrystallization during breccia formation were extensive on the LL chondrite parent body (Takeda et al. 1984), but no fractional crystallization took place from the melt.

Among Yamato (Y-) LL chondrites, we found the first evidence of a product of partial melting with albite and diopside assemblage in Y-74160 (Takeda et al. 1984). This assemblage is the first andesitic material in the solar system other than the Earth. The andesite was produced by a shock partial melting, but we also found such material in the silicate inclusions in the iron meteorites (Takeda et al. 2000; Takeda et al. 2003). Y-790964 and Y-790143 (Miyamoto et al. 1984; Yamaguchi et al. 1998) are unusual impact-melted LL chondrites and experienced

\footnotetext{
* Correspondence: takeda.hiroshi@it-chiba.ac.jp

'Department of Earth and Planetary Science, Graduate School of Sciences, University of Tokyo, Hongo, Tokyo 113-0033, Japan

${ }^{2}$ Forum Research, Chiba Institute of Technology, Narashino, Chiba 275-0016, Japan

Full list of author information is available at the end of the article
}

nearly total melting, yet partly preserve chondritic textures.

We performed mineralogical studies of the Y-981971, Y-793214, and Y-790782 LL chondrites to better understand surface materials of the Itokawa asteroid. We looked for the diopside-albite assemblage (andesitic material) together with olivine and orthopyroxene (Opx). Although these LL chondrites have brecciated and metamorphosed textures, remnants of chondrule are present. Total melting in much larger scale is recorded in a group of meteorite including howardite-eucrite-diogenite (HED) achondrites (e.g., Takeda 1997).

\section{Samples and methods}

Three polished thin sections (PTSs) of LL chondrites Y-981971,51-1 (Figure 1a), Y-793214,92-1 (Figure 1b), Y-790782,91-2 (Figure 1c), prepared at the National Institute of Polar Research (NIPR), were observed by a petrographic microscope. Y-981971 (Figure 1d), Y-793214 (Figure 1e), and Y-790782 (Figure 1f), were analyzed with a JEOL 8900 Electron Probe Microanalyzer (EPMA) (JEOL Ltd., Tokyo, Japan) at Atmosphere and Ocean Research Institute (AORI). Areal analyses of a region $30 \times 40 \mu \mathrm{m}$ of a granulitic clast were also obtained at AORI. Seven points were analyzed along the $X$ and $Y$ directions. (c) 2015 Takeda et al.; licensee Springer. This is an Open Access article distributed under the terms of the Creative Commons Attribution License (http://creativecommons.org/licenses/by/4.0), which permits unrestricted use, distribution, and reproduction in any medium, provided the original work is properly credited. 


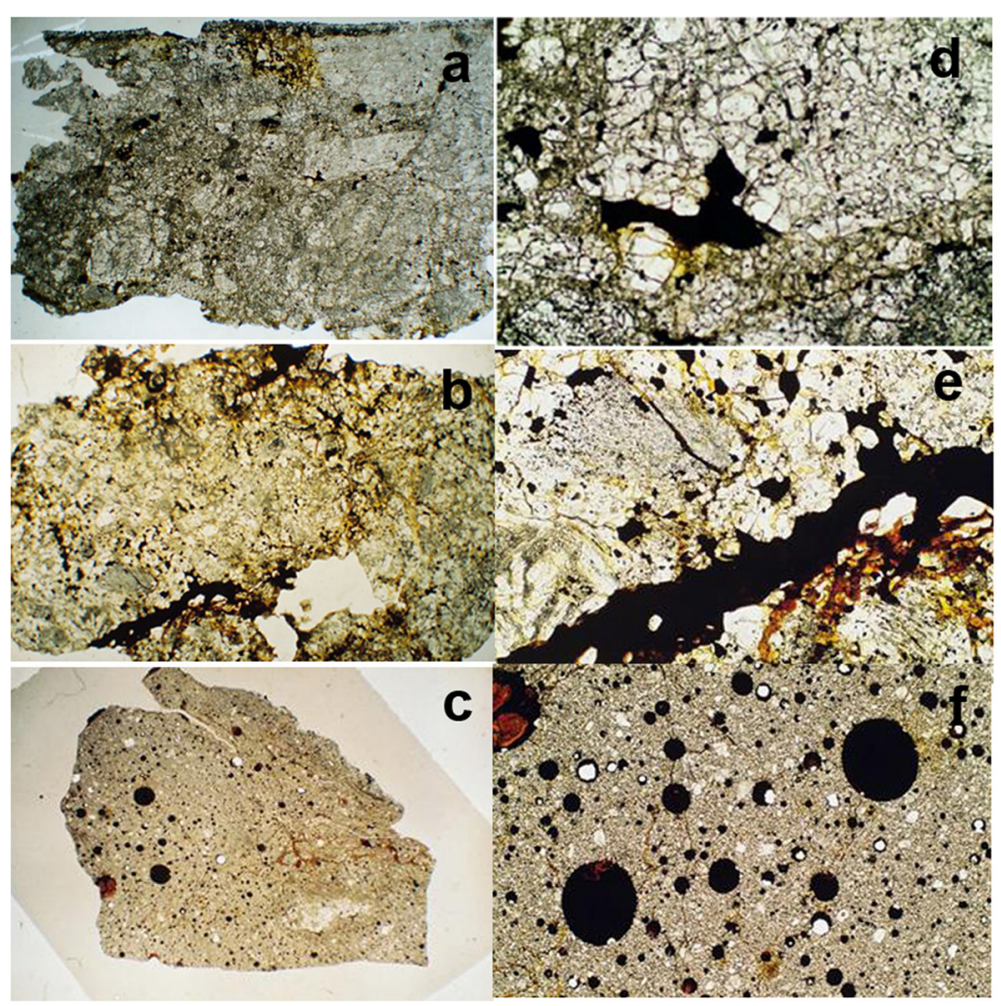

Figure 1 Photomicrograms of polished thin sections (PTS) of three LL chondrites from Antarctica. Left column; entire PTSs: open light; width is $1.2 \mathrm{~cm}$. (a) Breccia textures with many crystalline clasts in Y-981971,51-1. (b) The entire view of Y-793214,92-1 PTS. (c) An entire PTS of Y-790782,91-2 LL. Right column: enlarged views of those on the left side, width $1.3 \mathrm{~mm}$. Open polarized light: (d) an unbrecciated granulitic clast in Y-981971,51-1 LL. (e) An unbrecciated granulitic mass with an opaque vein in Y-793214 LL. (f) Opaque spherules in Y-790782 LL PTS.

\section{Results}

\section{PTS Y-981971}

Y-981971 shows breccia textures with many crystalline clasts (Figure 1a), which contain silicates with sub-rounded boundaries and a few opaque minerals filling interstices of silicate crystals. It is difficult to find remnants of chondrules, except for one part with metamorphosed barred olivine crystals. Former matrices between the bars now show crystalline textures. Chemical compositions of pyroxenes in Y-981971 are mostly uniform and are within the range of the LL chondrite.

In order to find the diopside-albite assemblage, modal abundances of minerals were obtained by the aerial analyses of JEOL 8900 EPMA for a selected area $30 \times 40 \mu \mathrm{m}$ above the irregular opaque grain in Figure 1d: olivine $53 \%$, augite 39 , Opx 5 , and albite 3 excluding a few lowsum analyses of grain boundaries, etc. The presence of augite and albite suggests presence of the andesitic material. Chemical compositions of olivines in $\mathrm{Mg}$ number $(=$ molar $\mathrm{Mg} /(\mathrm{Mg}+\mathrm{Fe}) \times 100)$ is $68 \mathrm{~mol} \%$. In a part of granulitic clasts, we found a sizable grain of albite in mafic silicates. The plagioclase in the clast has alkalirich composition $\mathrm{Ab}_{87.3} \mathrm{An}_{10.7} \mathrm{Or}_{1.9}$.
PTS Y-793214

PTS Y-793214 (Figure 1b) is listed as LL5 in the catalogue of NIPR, but we cannot detect any chondrule. It is different from a fragmental breccia as in Y-981971 PTS (Figure 1a). The overall texture is nearly crystalline granulitic feature with a few opaque veins. Along such veins, clear mafic silicate crystals are abundant with rounded gain boundaries (Figure 1e). The chemical composition of the mafic silicates is within the range of the LL chondrites.

\section{PTS Y-790782}

This PTS $(0.9 \times 0.8 \mathrm{~cm}$ in size $)$ consists of dark finegrained mafic silicates (Figure 1c). The PTS is characterized by many opaque spherules (Figure 1f). The presence of $\mathrm{Fe}, \mathrm{Ni}$, and $\mathrm{S}$ suggests that these spherules are products of partial melting of chondritic metals and sulfides. The opaque spherules distribute throughout the PTS (Figure 1c), indicating total melting. The texture is different from that of Y-790964 (Yamaguchi et al. 1998). A few clasts of crystalline materials are present in the matrices (Figure 1c). These clasts show a granulitic texture with an opaque vein. The matrix resembles devitrified glass, but an enlarged photograph (Figure 1f) 
shows that they are aggregates of fine fragments of low-Ca pyroxene and olivine. Some fragments are large enough to give single-mineral compositions, but fine materials between the fine fragments give compositions intermediate between low-Ca pyroxene and olivine. The pyroxene compositions are nearly uniform (average $\mathrm{Ca}_{5} \mathrm{Mg}_{73} \mathrm{Fe}_{22}$ ).

\section{Discussion}

Geothermometry based on the compositions of pyroxenes of the LL-group chondrites has been discussed by McSween and Patchen (1989). The sampled materials of Itokawa were thermally metamorphosed, as is the case for most ordinary chondrites. Nakamura et al. (2011) show that almost all of the olivine and pyroxene grains in the Itokawa dusts are quite uniform in composition, and the entire collection falls almost entirely within the LL field. To be heated sufficiently, the samples must have originated inside a much larger asteroid. The trend of a zoned grain in the Hayabusa dusts is different from that of the LL3 pyroxene and is similar to the pyroxene crystals in Y-790964 (Miyamoto et al. 1984). The zoning trends of the Itokawa dusts indicate that at least a part of the Itokawa asteroid body is melted by an impact event at high temperature. Our discovery of granulitic clasts with the diopside-albite assemblage indicates that there is an andesitic material (partial melt) in some parts of the LL parent body. The presence of the product of a partial melt in a chondrite parent body suggests that even the primitive solar system material, such as LL chondrites experienced strong thermal events. The granulitic textures in some lunar samples are widely believed to have formed deep in the lunar crust. The granulitic materials in the LL parent body may also have been formed at some depth of their parent body by an impact event. Granulitic breccias and granulites in lunar crust have been discussed by many lunar investigators (e.g., Lindstrom and Lindstrom 1986).

Products of high-temperature episodes in the solar system materials other than the terrestrial planets are represented by the differentiated achondrites. The mineralogy of Vesta, based on data obtained by the Dawn Mission (De Sanctis et al. 2012), is consistent with HED achondrites and confirmed the presence of the proposed layered crust model (Takeda 1979). It is important to recognize that high-temperature events took place in a region of the LL chondrite parent body, from where Itokawa and parent asteroids of the Antarctic meteorites were ejected. It is to be remembered that chondritic materials keep records of primitive solar system (McSween and Patchen 1989), but some parts are partly melted and heavily metamorphosed.

\section{Abbreviations}

HED: Howardite-eucrite-diogenite; Opx: Orthopyroxene.
Competing interests

The authors declare that they have no competing interests.

\section{Authors' contributions}

HT designed this study. HT and HN performed the mineralogical and petrological analyses. The study of three PTSs used in this work was enabled by the support of AY at National Institute of Polar Research (NIPR). YK participated in the design of the study. This study was partly supported by YY. HT drafted the paper. All authors discussed the results, read and approved the final manuscript.

\section{Acknowledgements}

We thank the NIPR for the samples and PTS preparation. We thank Prof. M Miyamoto and Dr. T Mikouchi of the Graduate School of Sciences, University of Tokyo, Prof. N Hasebe of Research Institute for Science and Engineering, Waseda University, Prof. T Nakamura of Tohoku University, and Dr. T Noguchi of Kyushu University for their discussion and support of our researches. This research was supported in part for NIPR, the Cooperative Program (No. 108, 2012) of AORI, the University of Tokyo, and for a program of Research Forum of Chiba Institute of Technology.

\section{Author details}

'Department of Earth and Planetary Science, Graduate School of Sciences, University of Tokyo, Hongo, Tokyo 113-0033, Japan. ${ }^{2}$ Forum Research, Chiba Institute of Technology, Narashino, Chiba 275-0016, Japan. ${ }^{3}$ Research Institute for Science and Engineering, Waseda University, Shinjuku, Tokyo 169-8555, Japan. ${ }^{4}$ National Institute of Polar Research, Tachikawa, Tokyo 190-8518, Japan. ${ }^{5}$ Department of Polar Science, School of Multidisciplinary Sciences, Graduate University for Advanced Studies, Tachikawa, Tokyo 190-8518, Japan. ${ }^{6}$ Institute of Space and Astronautical Science, Japan Aerospace Exploration Agency, Sagamihara, Kanagawa 252-5210, Japan. ${ }^{7}$ Department of Life and Environmental Sciences, Chiba Institute of Technology, Narashino, Chiba 275-0016, Japan.

Received: 13 February 2014 Accepted: 4 December 2014

Published online: 13 January 2015

\section{References}

Fujiwara A, Kawaguchi J, Yeomans DK, Abe M, Mukai T, Okada T, Saito J, Yano H, Yoshikawa M, Scheeres DJ, Barnouin-Jha O, Cheng AF, Demura H, Gaskell RW, Hirata N, Ikeda H, Kominato T, Miyamoto H, Nakamura AM, Nakamura R, Sasaki S, Uesugi K (2006) The rubble-pile asteroid Itokawa as observed by Hayabusa. Science 312:1330-1334

Lindstrom MM, Lindstrom DJ (1986) Lunar granulites and their precursor anorthositic norites of the early lunar crust. Proc $16^{\text {th }}$ Lunar Planet Sci Conf. J Geophys Res 91:D263-D276

McSween HY Jr, Patchen AD (1989) Pyroxene thermometry in LL-group chondrites and implication for parent body metamorphism. Meteoritics 24:219-226

Miyamoto M, Takeda H, Ishii T (1984) Mineralogical comparison and cooling history of lunar and chondritic vesicular melt breccias. J Geophys Res 89:11581-11588

Nakamura T, Noguchi T, Tanaka M, Zolensky ME, Kimura M, Tsuchiyama A, Nakato A, Ogami T, Ishida H, Uesugi M, Yada T, Shirai K, Fujimura A, Okazaki R, Sandford SA, Ishibashi Y, Abe M, Okada T, Ueno M, Mukai T, Yoshikawa M, Kawaguchi J (2011) Itokawa dust particles: a direct link between S-type asteroids and ordinary chondrites. Science 333:1113-1116

De Sanctis MC, Ammannito E, Capria MT, Tosi F, Capaccioni F, Zambon F, Carraro F, Fonte S, Frigeri A, Jaumann R, Magni G, Marchi S, McCord TB, McFadden LA, McSween HY, Mittlefehldt DW, Nathues A, Palomba E, Pieters CM, Raymond CA, Russell CT, Toplis MJ, Turrini D (2012) Spectroscopic characterization of mineralogy and its diversity across Vesta. Science 336:697-700

Takeda H (1979) A layered-crust model of a howardite parent body. Icarus 40:455-470

Takeda H (1997) Mineralogical records of early planetary processes on the howardite, eucrite, diogenite parent body with reference to Vesta. Meteoritics Planet Sci 32:841-853

Takeda H, Bogard DD, Mittlefehldt DW, Garrison DH (2000) Mineralogy, petrology, chemistry, and ${ }^{39} \mathrm{Ar}-{ }^{40} \mathrm{Ar}$ and exposure ages of the Caddo County IAB iron: evidence for early partial melt segregation of a gabbro area rich in plagioclase-diopside. Geochim et Cosmochim Acta 64(7):1311-1327 
Takeda H, Hsu W, Huss GR (2003) Mineralogy of silicate inclusions of the Colomera IIE iron and crystallization of Cr-diopside and alkali feldspar from a partial melt. Geochim et Cosmochim Acta 67(12):2269-2288

Takeda H, Huston TJ, Lipschutz ME (1984) On the chondrite-achondrite transition: mineralogy and chemistry of Yamato 74160 (LL7). Earth Planet Sci Lett 71:329-339

Yamaguchi A, Scott ERD, Keil K (1998) Origin of unusual impact melt rocks, Yamato-790964 and -790143 (LL chondrites). Antarct Meteorite Res 11:18-31

Submit your manuscript to a SpringerOpen ${ }^{\odot}$ journal and benefit from:

- Convenient online submission

- Rigorous peer review

- Immediate publication on acceptance

- Open access: articles freely available online

- High visibility within the field

- Retaining the copyright to your article

Submit your next manuscript at $\boldsymbol{\nabla}$ springeropen.com 